\title{
caa.reviews
}

critical reviews of books, exhibitions, and projects in all areas and periods of art history and visual studies published by the College Art Association
Follow us on
Eutiterer

CAP

March 17, 2010

Leonard Folgarait

Seeing Mexico Photographed: The Work of Horne, Casasola, Modotti, and Álvarez Bravo

New Haven: Yale University Press, 2008. 252 pp.; 40 b/w ills. Cloth $\$ 50.00$ (9780300140927)

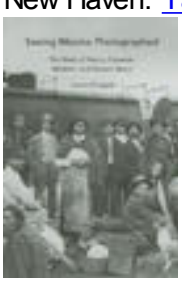

Esther Gabara

CrossRef DOI: 10.3202/caa.reviews.2010.28

Near the end of Seeing Mexico Photographed, Leonard Folgarait names the subject of inquiry that unfurls in his meticulously elaborated study of post-revolutionary Mexico: "photographic thinking" (180). We can say that this meditative book is itself an experiment in such thinking, which the author simultaneously describes and enacts in three distinctive chapters. While the historical period is more or less the same as his important study, Mural Painting and Social Revolution in Mexico, 1920-1940: Art of the New Order (New York: Cambridge University Press, 1998), the methodology and the knowledge produced here represent significant departures from this earlier work, and offer rich food for thought for scholars and students of visual culture, Mexican history, and photography.

Folgarait's central concern is how photographic thinking produces new knowledge about the production of historical knowledge itself, and the political uses of this history. He carefully explains that the book is not about the events or subjects that appear in the photographs, but rather about how to "see how something looks photographed" (2). This phrasing, borrowed from photographer Garry Winogrand, forms the basis for the shifting between what only sounds like a form of medium specificity-what photography itself shows us to see-and the politico-historical moment pictured within those images. Folgarait specifies that this approach reveals historical and social conditions, rather than entering into a debate about the veracity or beauty of a particular event captured on film. Throughout, he does a masterful job of slipping from close readings and interpretations of the composition, lighting, and mood of carefully selected photographs to detailed examinations of the complex and hotly debated competition for political power and ideological legitimacy in the fifteen years following the Mexican Revolution (1910-1920).

Chapter 1 examines photojournalists Walter H. Horne and Agustín Víctor Casasola, briefly setting the stage for the discussion of post-revolutionary Mexico with images of the armed conflict that would shape all other political conflicts in the country during the twentieth century and into the twenty first. As is generally accepted in the scholarly literature about this period, Seeing Mexico Photographed sets out how the transition from the massive disruption of the revolution to a centralized nation state required the organization of images and ideas about modernity, nation, and mexicanidad (Mexican-ness). Folgarait finds that the "'style' by which nationhood was imagined at that time is figured in the very precise manner of photographic presentation" (10; emphasis in original), particularly images of masses of people in the streets. Here we see the first instance of the "photographic thinking" he studies and enacts. Like the idea of the "masses" at the heart of revolutionary ideology, which was pictured so often in photographs, photography itself is fluid and constant. If the masses were photographed to provide the "image of a consolidated citizenry, assimilated into unity in spite of their obvious differences" (28), photographs are images that offer the appearance of stillness and coherence, and yet encompass a myriad of contradictory meanings. Perhaps the most innovative insights in this chapter are the parallels Folgarait draws between the photographic style of national identity and the political plans (the Plan de San Luís de Potosí and the Plan de Ayala) drawn up by revolutionary leaders Francisco Madero and Emiliano Zapata; he strikingly concludes that the photographs as much as these plans present the masses "self-consciously posing to a nationwide audience" (28). 
Dedicated to Italian-born photographer, model, actress, and political activist Tina Modotti, chapter 2 takes on two key topics in Modotti scholarship: the relationship of her work to propaganda, and the status of her biography in analyzing the work. Folgarait's solution is to allow the complexity of the images to answer both issues, and his sustained engagement with Modotti's photographs draws out the contradictions of art and politics in post-revolutionary history. His central argument here is that in her highly composed photographs, multiple beings and moments are fused together to create polysemic images. Through his readings of her still lifes, images of mass demonstrations, and portraits, Folgarait demonstrates that Modotti shows that "a revolutionary subject is more a moment in flux, a dynamic movement, than an object or idea or even measurable in quantitative terms"; it is, like photographs themselves, "a performance of several possibilities" (95).

Folgarait delves further into the contradictions bound up in Modotti as a revolutionary subject. He stresses that, as much as she was an unflaggingly conscientious and loyal member of the Communist Party, during her final months in Mexico she spent her time making portraits of the Mexico City elite. The form of photographic thinking that addresses these tensions emerges in Folgarait's interpretation of the impact of her trip to Tehuantepec, Oaxaca, in 1929. Many artists and writers made this same trip throughout the twentieth century, eager to find (and invent) the exotic, matriarchal culture where a racialized, female sexuality was free of the taboos of the Catholic Church (see the exhibition catalogue Del istmo y sus mujeres: Tehuanas en el arte mexicano, Claudio Barrón, Ana Paulina Gámez, and Luis Martín Lozano, eds., Ciudad de Mexico: Museo Nacional de Arte, 1992). Folgarait argues that in fleeing to Tehuantepec from political danger due to her work with the Communist Party, Modotti learns a great deal from the rebellious tehuanas' evasion of her camera. They teach her a "strategy of disappearance" (144), which in turn teaches us about the complexity of "political visibility." Folgarait details this visibility in his narrative of Modotti's highly publicized prosecution for the murder of her lover, Communist leader Julio Antonio Mella, and her ultimate expulsion from Mexico, which was motivated by politics but cloaked in the language of visuality and sexual immorality. All of these elements contribute to Folgarait's broader argument about the complexities of seeing and inhabiting revolutionary subjectivity, and the relationship between the individual revolutionary subject (here, Modotti's biography) and formal issues in art making and viewing.

Chapter 2 is the longest of the book, spanning 120 pages in contrast to the 20 pages of chapter 1 and 50 pages of chapter 3 . While the chapter is compelling, it loses the sharp focus of the other chapters, and the imbalance does some harm to the pacing and coherence of the book as a whole. Additionally, as much as Folgarait admirably dedicates significant attention to the question of gender in Modotti's work and politics, his lack of direct engagement with feminist theory from either Mexico or the Euro-American academy makes his conclusions ultimately fall short of their initial promise. For instance, he concludes that: "Perhaps feminism is a good term to describe the behavior of one who escapes the social constructions of gender expectations and finds that her intellect, art, sex, and social aspirations are enough to drive her being" (117). I am not sure that recent feminist theory would accept such a clean escape by any woman from such norms. Furthermore, Folgarait's analysis of Modotti's cross-dressing, both as a man and as a tehuana, would benefit from the extensive feminist literature on performance and race addressed in scholarship from Mexico and the United States. 1

Folgarait concludes with a chapter dedicated to Manuel Álvarez Bravo, in which he proposes that even before Álvarez Bravo was celebrated as Mexico's greatest and most recognized photographer, "the situation of photography within photography was there all along and established a habit of viewing these images that led to the current and uncritical acceptance of them as the highest attainment and very definition of Mexican photography" (154). Álvarez Bravo becomes the culmination of Folgarait's argument about photography and history, as in his photographs "the image assum[es] a tremendous transformative power over the event" (154). The most compelling analysis here demonstrates how highly formalist images, and a formalist analysis of them, reveal the operation of political power in post-revolutionary Mexico. That is, Álvarez Bravo's photographs deal with the challenge of invisibility that Modotti too sought to address. While they evidently do not represent invisibility, they reveal a condition of political life in Mexico in which the real power was unseen (for more on how Álvarez Bravo includes the invisible in his photographs, as an ethics as much as a politics, see my Errant Modernism: The Ethos of Photography in Mexico and Brazil, Durham: Duke University Press, 2008). Under Folgarait's discerning eye, photographs that constantly refer to themselves as photographs-from the famous Striking Worker Assassinated (1934) to Fire Workers (1935)_frame a form of photographic political thinking necessary to navigate the post-revolutionary consolidation of power under Calles and the maximato.

At times, however, Folgarait's insistence on Álvarez Bravo as the creator of photography about/within photography becomes perhaps overly determinate. Folgarait describes Álvarez Bravo as a photographer of death, and finds in death the perfect photographic subject that permits us to "indulge fully and only in the idea of representation, rather than to act it out, as death is unknowable and thus unrepresentable" such that it causes us to "fall[s] back, by definition, to the hyper metadiscourse of self-reflexivity" (176; emphasis in original). Anthropologist Claudio Lomnitz has traced the long and shifting history of death in Mexico, from pre-conquest indigenous civilizations to the recent popularity of the religious sect around "Santa Muerte" (Saint Death) (Claudio Lomnitz, Death and the Idea of Mexico, New York: Zone Books, 2005). His study departs not from the premise that death is unrepresentable but rather that "if death is the mirror of life, so too, is life the mirror of death" (15). Mexico, with its widely known if often exoticized 
imaginary of death, is a rich and particular terrain for this social history and analysis. In fact, Lomnitz shows that during the twentieth century in Mexico, particularly in the 1920s and 1930s, "a gay familiarity with death became a cornerstone of national identity": the very national identity to which Folgarait pays such close attention (20). As the post-revolutionary regimes' cultural ideology was filled with representations of Mexicans' intimate relationship to death, the treatment of it in Álvarez Bravo's photographs requires both a more varied and specifically located treatment.

Folgarait's study contributes greatly to the literature on photography, both within modernist studies more generally and the history of photography in Latin America in particular. Seeing Mexico Photographed also advances the project of visual studies, contributing the idea of "photographic thinking" to its stock of methodologies and theories. Finally, it offers an innovative framework for the extraordinarily difficult task of comprehending the contradictory and hidden power dynamics in post-revolutionary Mexico. As the centennial of the Mexican Revolution fast approaches, and the rhetoric of nationalism grounded in the images generated during this period heightens, such new methods and insights are increasingly necessary and valuable. $\stackrel{2}{2}$

\section{Esther Gabara}

Associate Professor, Departments of Romance Studies, and Art, Art History, \& Visual Studies, Duke University egabara@duke.edu

1 Some sources to consult: Diana Taylor, Archive and Repertoire: Performing Cultural Memory in the Americas, Durham: Duke University Press, 2003; Norma Klahn, "Travesías/Travesuras: Des/Vinculando Imaginarios Culturales," Las nuevas fronteras del siglo xxi=New frontiers of the 21st. century, in eds. Norma Klahn, et al., Mexico: La Jornada, 2000; the Mexican feminist journals Debate feminista and Fem; and Mónica Mayer, Rosa chillante: Mujeres y performance en México, Mexico: AVJ with a grant from the Fondo Nacional para la Cultura y las Artes, 2004.

$\underline{2}$ See the Mexican government's website, http://www.bicentenario.gob.mx/, which includes a selection of revolutionary photographs similar to those reproduced in chapter 1 of Seeing Mexico Photographed.

Copyright @2010 College Art Association, Inc. Terms of Use

275 Seventh Avenue, New York, NY 10001 | T: 212-691-1051 | F: 212-627-2381 | caareviews@collegeart.org 